\title{
Studying Properties of Prospective Biologically Active Extracts from Marine Hydrobionts
}

\author{
Olga P. Chzhu ${ }^{a^{*}}$, Daredzhan E. Araviashvili a, Irina G. Danilova ${ }^{\text {a }}$ \\ ${ }^{a}$ Research Institute of Medical Primatology, Sochi, Russia
}

\begin{abstract}
Biologically active substances (BAS) extracted from marine hydrobionts are characterized by high diversity and efficiency. They are represented by carotenoids, phospholipids, saponins and other compounds possessing high antioxidant (AOA), antitumor, immunomodulatory, radioprotective, and hypolipidemic activities. Because of extremely high marine BAS activity, the BAS dose necessary for treatment and prevention of many diseases is very small. The aim of present work was to assess biological properties of BAS complexes extracted from Black Sea marine inverterbrates for their following using in pharmacological preparations including liposomal drug delivery. BAS complexes were extracted from marine invertebrate tissues by two-phase extraction in combination with ultrasonication. Antioxidant activity of BAS extracts was determined with potassium permanganate discoloration method in an aqueous sulfuric acid medium. Antimicrobial activity was investigated by germination of BAS extracts. BAS influence on lymphocyte proliferative activity was studied with help of cytogenetic analysis. In this paper, the assessment of antioxidant, antimicrobial and mitogenic activities of biologically active complexes extracted from marine invertebrate tissues is presented. BAS properties in the oil and alcohol-water phases are compared. For the first time BAS complexes from Black Sea invertebrates are extracted by the resource-light method of two-phase extraction in combination with ultrasonication. Conditions for obtaining BAS extracts with optimal characteristics are proposed.
\end{abstract}

Keywords:

Biologically Active Substances; Marine Hydrobionts;

Antioxidative Activity;

Mitogenic Activity.

Article History:

Received: 31 July 2019

Accepted: 15 December 2019

Published: 01 February 2020

\section{1- Introduction}

The uniqueness of marine biologically active substances is associated with aqueous living environment of hydrobionts characterized by high salt content, low or no light, extremely low or high temperatures and high pressure. This ensures the difference between marine organisms and their metabolites from terrestrial ones. As natural sources, marine hydrobionts are characterized by the diversity and high efficiency of biologically active substances.

Hydrobionts of marine areas, especially invertebrates such as crustaceans, mollusks and echinoderms differ from many terrestrial and aquatic organisms in significant variety of metabolites The dominant part of these metabolites is represented by functional compounds: flavonoids, carotenoids, phospholipids, saponins, polyunsaturated fatty acids omega three and omega six and other substances possessing high antioxidative, antitumor, immunomodulatory, radioprotective, and hypolipidemic activities [1]. For example, alkaloid fistularin extracted from marine sponge effectively synergizes with the drug Venetoclax and can be used for acute myeloid leukemia treatment [2]. Anthraquinones from marine filamentous fungi are promising agents for treatment of multidrug resistant tumour cells and in chemotherapy of various cancers: hepatocellular carcinoma, human pancreatic and gastric cancers, bladder cancer, leukaemia [3]. The large number of triterpene saponins, cerebrosides and fucosylated chondroitin sulfates extracted from sea cucumber induce malignant cell apoptosis [4]. The unusual source of phospholipase A2 possessing pronounced antiretroviral activity is the red lionfish venom [5]. Peptides and depsipeptides from marine sponges inhibit

\footnotetext{
* CONTACT: Olga.chzhu@ mail.ru

DOI: http://dx.doi.org/10.28991/esj-2020-01208
}

(C) 2019 by the authors. Licensee ESJ, Italy. This is an open access article under the terms and conditions of the Creative Commons Attribution (CC-BY) license (https://creativecommons.org/licenses/by/4.0/). 
HIV-1 entry into host cells, some peptides are effective against vesicular stomatitis virus, amphotropic murine leukemia virus, equine rhinovirus, coxsackie virus A-21 and vaccinia virus [6]. From marine sources was extracted the large number of xanthone derivatives with antiviral, antibacterial, antiparasitic and antifungal activities [7]. At the same time, because of extremely high BAS activity, the dose of marine BAS necessary for the treatment and prevention of many diseases is very small [8].

In this respect, special attention should be given to flavonoids. They possess pronounced antoixidative activity. These substances favourably influence on cardiovascular system preventing chronic cardiovascular diseases. Flavonoids decrease the level of low density lipoproteins, regulate blood pressure, decrease permeability and fragility of capillaries, increase erythrocyte membrane elasticity and prevent thrombus formation. Also they improve metabolism and promote the body weight decrease. These substances influence on insulin resistance, an additional 500mg daily intake decrease diabetes risk by 5\%. Flavonoids suppress tumor growth. The high daily intake of flavonoids decrease the ovarian cancer risk by $18 \%$, the gastroenteric cancer and anatomical airway risk by $33 \%$, the lung cancer risk by $16 \%$. Flavonoids are able to protect neurons from oxidative damage and promote neuron regeneration. Flavonoid rich diet decrease Parkinson disease risk by $40 \%$ and it is also helpful for Alzheimer patients. Flavonoids suppress virus growth, for example, flavones are effective against hepatitis B, and kaempferol can be used in antiretroviral therapy [9].

Carotenoids and chlorophylls are pigments found in algae and even in some bacteria, in addition to land plants. Besides high antioxidative activity, carotenoids are able to fit into cell membranes and to decrease membrane fluidity, whereas the high membrane fluidity is characteristic for tumour cells [10]. Also carotenoids influence on cell signaling pathways by inducing connexin-43 protein production. Connexins are transmembrane proteins which form gap junctions and ensure cell-cell interactions. At the same time, separated cells not contacting with each other were found in tumours [11]. The outstanding features of carotenoids isolated from marine hydrobionts are their oxidized state and antioxidative activity, which is 10 times larger than one of $\beta$-carotene. It is suggested that marine carotenoid activity is defined not only by a number of unsaturated ethylenic bonds, but also the more balanced chemical structure with $\pi$-electron system [12].

Another important extracted substances are phospholipids. Phospholipids are part of cells of all living beings. The normal functioning of cell membranes depends on the microviscosity of phospholipid layer and the mobility of phospholipid molecules. Phospholipids perform a transport function, determine the permeability of cell membranes, take part in the cell response to some external influences, for example, the action of hormones, neurotransmitters and growth factors. Antioxidative properties of phospholipids are manifested in the deactivation of peroxides, highly reactive oxygen free radicals, xenobiotics and prevention of free radical lipid peroxidation [13].

Phospholipids are widely used for preparation of liposomal structures carrying medical preparations. Liposomes are very good in drug delivery to liver, bone marrow, lymphatic nodes [14]. Liposomes are non-toxic, biodegradable and directly absorbed by cells or their membrane fuses with cell membrane leading to intracellular delivery of their content.

The aim of our work was to extract and to assess biological properties of BAS complexes obtained from marine inverterbrate tissues. Obtained results clarified if these complexes could be considered both as individual pharmacological preparations and as components for liposomal structure preparation.

As objects of research were selected BAS complexes extracted from: 1) mussels of the genus Mytilus (habitat - the Black Sea area); 2) shellfishes of the genus Rapana (habitat - the Black Sea area).

\section{2- Materials and Methods}

Complexes of biologically active substances were extracted from marine invertebrate tissues by two-phase extraction in combination with ultrasonication. The method of two-phase extraction allows to use the two-phase solvent system (alcohol-water mixture/oil) as an extractant and to simultaneously extract hydrophilic and hydrophobic substances from raw materials. Predominantly hydrophilic substances remain in the alcohol-water phase, and lipophilic ones pass into the oil. The combination of two-phase extraction with ultrasonication provides the deeper solvent penetration into the material with cell structure, reduces the processing time, provides a higher product yield and reproducibility, reduces solvent consumption, increases the speed of process, allows to extract thermolabile substances [15].

Extraction was performed at room temperature and periodical stirring. The frozen raw material was mechanically grinded up. Then weighed quantity of the raw material, 5 grams, was placed into a flat bottomed flask of $250 \mathrm{ml}$ capacity and $96 \%$ ethanol was added for 1.2 - 2 hours to moister material. After that, $50 \mathrm{ml}$ of olive oil and distilled water were added to satisfy the ratio 1 part of raw material / 10 parts of oil / 10 parts of $70 \%$ ethanol. Ultrasonication was performed in the frequency range $2 \cdot 10^{4}-2 \cdot 10^{8} \mathrm{~Hz}$.

For obtained BAS extracts, antioxidative activity was determined by a method that allows screening drug plants, phytopreparations and biologically active substances with high antioxidative activity and includes the interaction of analyzed sample with potassium permanganate until discoloration of the latter in an aqueous sulfuric acid medium at 
room temperature [16]. In acid medium, a reducing agent reduces $\mathrm{Mn}^{7+}$ to $\mathrm{Mn}^{2+}$. The solution of $0.05 \mathrm{~N}$ potassium permanganate in $0.24 \mathrm{M}$ sulfuric acid is titrated by the analyzed sample solution until discoloration. The antioxidative activity (" $\mathrm{B}$ " in formula) is expressed in terms of (quantity of antioxidants, mg) / (weighed quantity of the raw material, g) and calculated according to:

$$
B=\frac{C_{k} V_{k} V_{o}}{V_{x} m}
$$

Where $C_{k}$ - concentration of quercetine in solution used for titration of $1 \mathrm{ml}$ potassium permanganate, $\mathrm{mg} / \mathrm{ml}$; $\mathrm{V}_{\mathrm{k}}-$ volume of quercetine solution used for titration of $1 \mathrm{ml}$ potassium permanganate, $\mathrm{ml} ; \mathrm{V}_{\mathrm{o}}$ - volume of investigated potassium permanganate solution, $\mathrm{ml} ; \mathrm{V}_{\mathrm{x}}$ - volume of studied sample solution necessary for titration of $1 \mathrm{ml}$ potassium permanganate, $\mathrm{ml} ; \mathrm{m}$ - weight of studied sample, $\mathrm{g}$.

The calculated B is the quantity of antioxidants in quercetine equivalents in $1 \mathrm{~g}$ or $1 \mathrm{ml}$ of studied sample. The higher $\mathrm{B}$, the higher AOA of sample.

Research of antimicrobial activity was carried out by germination of extracts with optimal antioxidative activity values in the oil and alcohol-water phases (ultrasonication time was 3 hours) in a ratio of $20 \mu 1$ of extract per $1 \mathrm{ml}$ of nutrient medium. The obtained samples were thermostated and visual observation was conducted for a long time.

Assessment of proliferative activity (growth and mitotic activity) of lymphocytes under the BAS complex influence was carried out by cytogenetic analysis (preparation of metaphase chromosome samples, chromosome staining, quantitative analysis of metaphase plates) after standard in vitro cultivation of non-human primate peripheral blood lymphocytes (crab-eating macaque, Adler colony animal number № 44802) with some modifications [17]. The flowchart showing the methodology is presented on Figure 1.

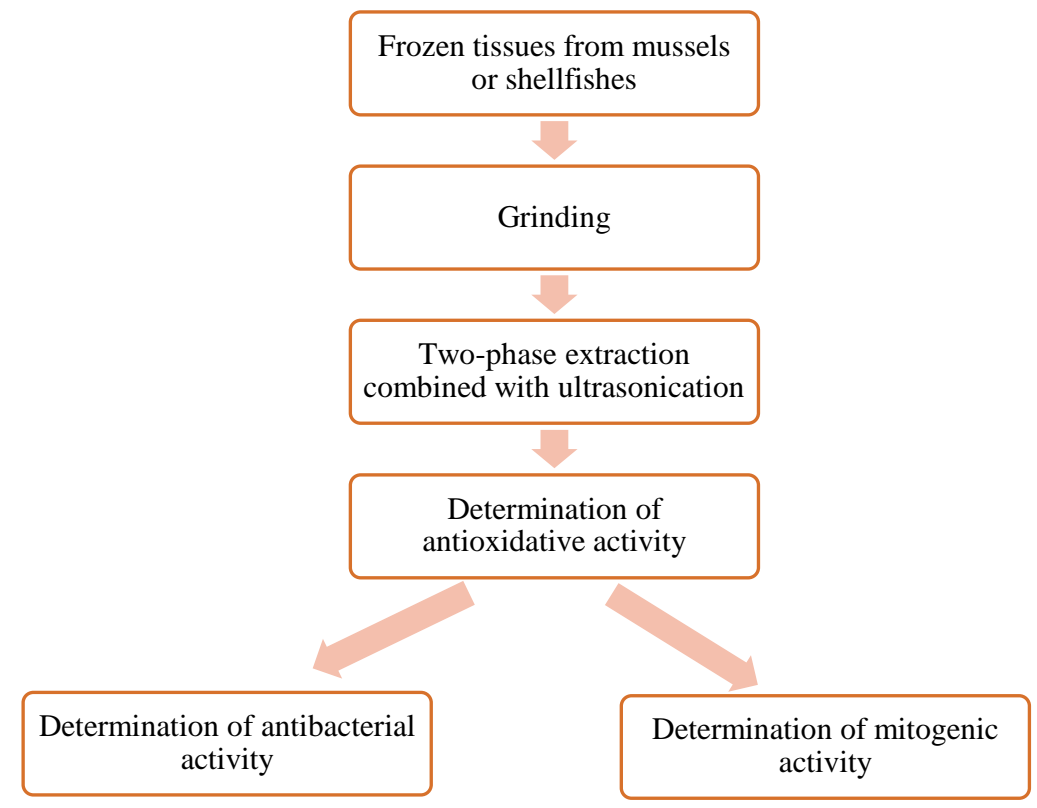

Figure 1. The research methodology flowchart.

\section{3- Results and Discussion}

Results of BAS antioxidative activity assessment are presented in Table 1 and Figures 2 to 4 . 
Table 1. Antioxidative activity (AOA) of BAS complexes from mussels in the oil phase and alcohol-water phase, depending on the ultrasonication time (in terms of the amount of biologically active substances with antioxidative properties, $\mathrm{mg} / \mathrm{ml}$ )

\begin{tabular}{|c|c|c|c|c|c|c|c|}
\hline $\begin{array}{c}\text { AOA } \\
\text { of extracts, } \\
\text { mg/ml }\end{array}$ & $\begin{array}{l}\text { Control sample } \\
\text { no sonication, } \\
\text { stirring } 96 \text { hours }\end{array}$ & $\begin{array}{c}\text { Sample } 1 \\
\text { (sonication } \\
1 \text { hour) }\end{array}$ & $\begin{array}{r}\text { Sample } 2 \\
\text { (sonication } \\
2 \text { hours) }\end{array}$ & $\begin{array}{c}\text { Sample } 3 \\
\text { (sonication } \\
3 \text { hours) }\end{array}$ & $\begin{array}{c}\text { Sample } 4 \\
\text { (sonication } \\
6 \text { hours) }\end{array}$ & $\begin{array}{c}\text { Sample } 5 \\
\text { (sonication } \\
9 \text { hours) }\end{array}$ & $\begin{array}{l}\text { Sample } 6 \\
\text { (sonication } \\
12 \text { hours) }\end{array}$ \\
\hline Oil phase & 0.76 & 0.96 & 1.01 & 1.17 & 1.09 & 1.35 & 1.58 \\
\hline Alcohol-water phase & 0.53 & 0.65 & 0.61 & 0.71 & 0.56 & 0.57 & 0.54 \\
\hline
\end{tabular}

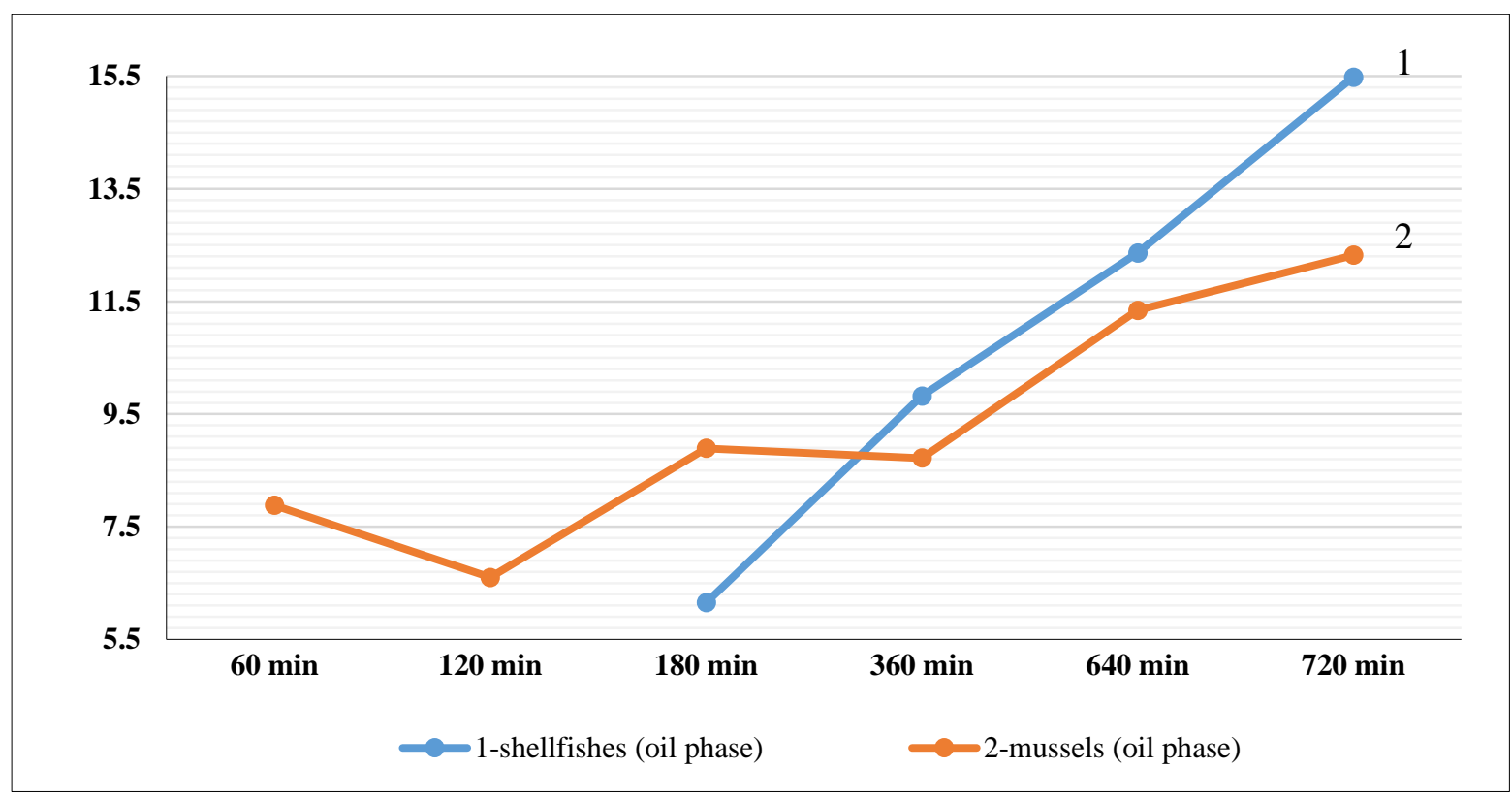

Figure 2. Antioxidantive activity of BAS complexes from mussels and shellfishes in the oil phase (in terms of the amount of biologically active substances with antioxidative properties, $\mathrm{mg} / \mathrm{g}$ ).

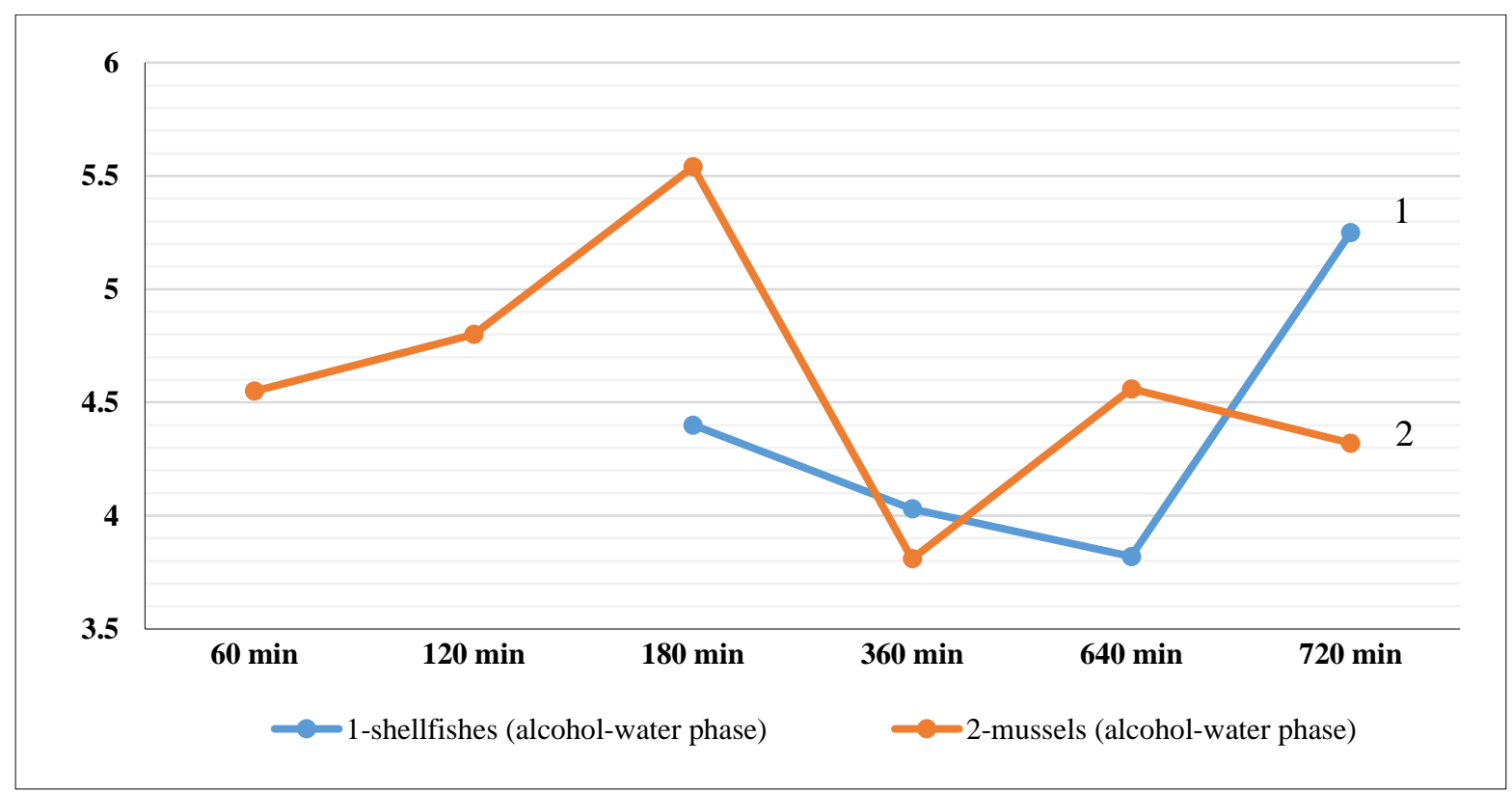

Figure 3. The antioxidative activity of BAS complexes from mussels and shellfishes in the alcohol-water phase (in terms of the amount of biologically active substances with antioxidative properties, $\mathbf{m g} / \mathrm{g}$ ). 


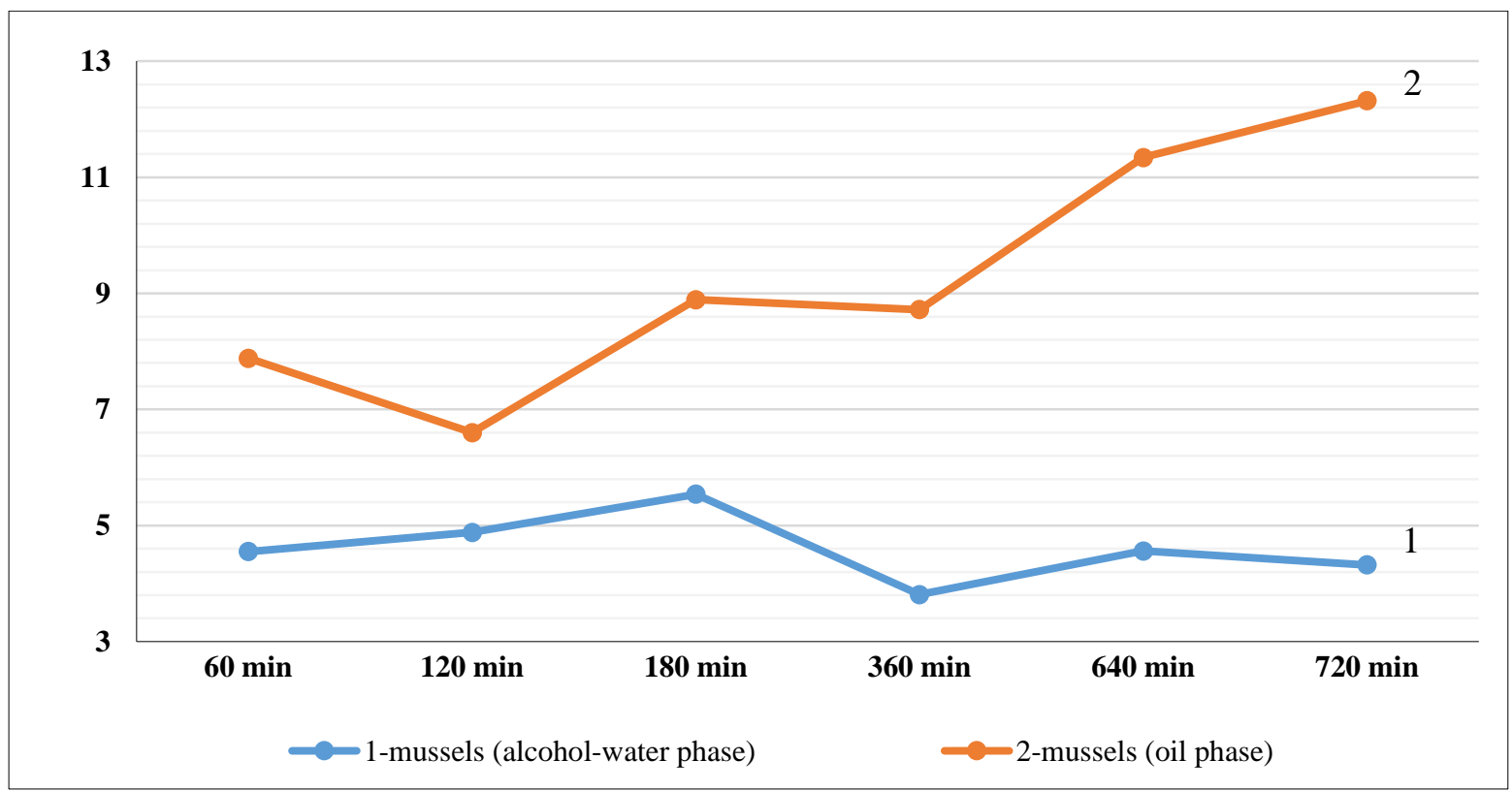

Figure 4. Antioxidative activity of BAS complexes from mussels, in the alcohol-water and oil phases (in terms of the amount of biologically active substances with antioxidative properties, $\mathrm{mg} / \mathrm{g}$ ).

As it is seen from Figure 2, at the end of experiment (720 min), oil extracts from shellfishes showed higher AOA than mussels. The difference between shellfishes and mussels was low, $4 \mathrm{mg} / \mathrm{g}$, and it is difficult to discuss its' importance, but whereas the small BAS concentrations are effective, an additional $4 \mathrm{mg}$ may positively contribute to medicinal effects of preparations. Decrease in AOA of mussels at $120 \mathrm{~min}$ and $360 \mathrm{~min}$ is the most probably caused by ultrasound influence and partial destroy of some substances. If to consider an alcohol-water phase, the best point is 180 min when AOA of mussels is equal to $5 \mathrm{mg} / \mathrm{g}$. Shellfish extract reaches the same value only at $720 \mathrm{~min}$. Comparison Figures 2 and 3 shows that if to neglect the fact of non-maximal antioxidative activity of oil-phase extracts from mussels and shellfishes, the optimal ultrasonication time is $180 \mathrm{~min}$ ( 3 hours).

Analysis of obtained results allowed to make following conclusions. Antioxidative activity increases with the ultrasonication time. The antioxidative activity of extracts in an oil phase is $2-3$ times as much as activity of extracts in an alcohol-water phase, isolated under similar conditions. The antioxidative activity of extracts isolated from shellfishes is higher than activity of extracts isolated from mussels, when the ultrasonication time is from 6 to 12 hours. The ultrasonication time is 3 hours to obtain extracts with optimal AOA values in the oil and alcohol-water phases. The combination of two-phase extraction with ultrasonication allows to achieve within 60-180 minutes antioxidative activity values equal to values of extracts obtained by stirring for 96 hours (the time depends on properties of the starting material).

Antimicrobial activity of obtained extracts was determined by germination in a nutrient medium. Within 30 days from the sowing date, germination of the nutrient medium was not observed, that may be an indirect confirmation of the pronounced antimicrobial activity of studied samples.

The growth and mitotic activity of peripheral blood lymphocytes were evaluated under the influence of biologically active substances extracted from mussel tissues, in the oil and water-alcohol phase and ultrasonication time 3 hours. The level of mitotic activity for the control sample was 18 mitoses per 1000 cells; for the sample with added BAS in wateralcohol phase -22 mitosis; for the sample with added BAS in the oil phase -48 mitoses.

Influence of biologically active extracts obtained from marine inverterbrate tissues is multiple. Components of extracts can permeate in cells for future use in cell metabolism. Also they can bind with cell surface and to protect cell from unfavorable external influence.

As it is mentioned in literature, a high polarity solvent, ethanol in our studies, results to extraction of water soluble flavonoids, alkaloids, terpenoids and glycosides [18]. So, the obtained alcohol-water phase contained these substances. The oil phase included lipophilic compounds: phospholipids, carotenoids, aglycons of flavonoids and xanthones, polyunsaturated fatty acids.

Antioxidative activities of extracts obtained from mussels and shellfishes have not been extensively investigated. The search "biologically active substances from mussels" or "from shellfishes" in PubMed gives totally 10 papers not concerning AOA at all. At the same time, algae were studied. As it was described in [19], comparison of extracts from green algae Enteromorpha compressa (syn. Ulva compressa), Cladophera fulvescens, Chaetomorpha moniligera, and 
Ulva pertusa showed that ethanol extracts from green alga Ulva pertusa possessed AOA of flavonoids equal to 27.4 $\mathrm{mg} / \mathrm{g}$ (in quercetine equivavelnts).

Phospholipids from the oil extracts can be used in preparation of liposomal structures. In this case, special drugs or components of the alcohol-water phase can be placed inside. There is our positive experience on liposome construction using peloids (non-marine substances): water peloid extract (64\%), lipid peloid extract (25\%), water complex of humic acids $(10 \%)$ and stabilizer containing phospholipids (1\%) [20].

\section{4- Conclusion}

Marine hydrobionts are the source of biologically active substances showing a large number of activities, such as antioxidative, antimicrobial and membrane protective. High biological activities are necessary in pathogenetic therapy of many diseases, including illnesses accompanied by secondary immune deficiency syndrome. Lymphocytes realize not only the immune response, but also take part in processes of maintaining homeostasis, inflammation and regeneration, affect the mitotic activity of various tissues, stimulate and regulate their growth. In present paper, biologically active extracts were obtained from marine inverterbrate tissues by two-phase extraction combined with ultrasonication. This method allowed to simultaneously obtain the alcohol-water and oil phases. Extracts showed pronounced antioxidative and mitogenic activities. Oil extracts possessed higher antioxidative activity. Extracts with optimal antioxidative activity values were obtained in the oil and alcohol-water phases at the ultrasonication time equal to 3 hours. Phospholipid complexes contained in extracts can be immediately used in preparation of liposomal structures carrying drugs and applied in treatment of cancer, diabetes, infectious diseases, skin leisures, and also in cosmetology. Results of our studies allow to recommend the obtained extracts of biologically active substances as components of pharmacological preparations with antioxidant effect and cellular recovery and protection from oxidation processes.

\section{5- Conflict of Interest}

The author declares that there is no conflict of interests regarding the publication of this manuscript. In addition, the ethical issues, including plagiarism, informed consent, misconduct, data fabrication and/or falsification, double publication and/or submission, and redundancies have been completely observed by the authors.

\section{6- References}

[1] Sansone, Clementina, and Christophe Brunet. "Promises and Challenges of Microalgal Antioxidant Production." Antioxidants 8, no. 7 (June 27, 2019): 199. doi:10.3390/antiox8070199.

[2] Florean, Cristina, Kyung Kim, Michael Schnekenburger, Hyun-Jung Kim, Céline Moriou, Cécile Debitus, Mario Dicato, Ali AlMourabit, Byung Han, and Marc Diederich. "Synergistic AML Cell Death Induction by Marine Cytotoxin (+)-1(R), 6(S), 1'(R), 6'(S), 11(R), 17(S)-Fistularin-3 and Bcl-2 Inhibitor Venetoclax.” Marine Drugs 16, no. 12 (December 19, 2018 ): 518. doi:10.3390/md16120518.

[3] Fouillaud, Mireille, Mekala Venkatachalam, Emmanuelle Girard-Valenciennes, Yanis Caro, and Laurent Dufossé. "Anthraquinones and Derivatives from Marine-Derived Fungi: Structural Diversity and Selected Biological Activities." Marine Drugs 14, no. 4 (March 25, 2016): 64. doi:10.3390/md14040064.

[4] Khotimchenko, Yuri. "Pharmacological Potential of Sea Cucumbers." International Journal of Molecular Sciences 19, no. 5 (May 2, 2018): 1342. doi:10.3390/ijms19051342.

[5] Sommeng, Andy Noorsaman, R. Muhammad Yusuf Arya, Mikael Januardi Ginting, Diah Kartika Pratami, Heri Hermansyah, Muhamad Sahlan, and Anondho Wijanarko. "Antiretroviral Activity of Pterois Volitans (red Lionfish) Venom in the Early Development of Human Immunodeficiency Virus/acquired Immunodeficiency Syndrome Antiretroviral Alternative Source." February-2019 12, no. 2 (February 2019): 309-315. doi:10.14202/vetworld.2019.309-315.

[6] Da Mata, Élida Cleyse Gomes, Caroline Barbosa Farias Mourão, Marisa Rangel, and Elisabeth Ferroni Schwartz. “Antiviral Activity of Animal Venom Peptides and Related Compounds.” Journal of Venomous Animals and Toxins Including Tropical Diseases 23, no. 1 (January 6, 2017). doi:10.1186/s40409-016-0089-0.

[7] Loureiro, Daniela R. P., José X. Soares, Joana C. Costa, Álvaro F. Magalhães, Carlos M. G. Azevedo, Madalena M. M. Pinto, and Carlos M. M. Afonso. "Structures, Activities and Drug-Likeness of Anti-Infective Xanthone Derivatives Isolated from the Marine Environment: A Review.” Molecules 24, no. 2 (January 10, 2019): 243. doi:10.3390/molecules24020243.

[8] Krivoshapko, O. N., A. M. Popov, A. A. Artyukov, and E. Y. Kostetsky. "Peculiarities of the Corrective Effects of Polar Lipids and Bioantioxidants from Sea Hydrobionts in Impairments of Lipid and Carbohydrate Metabolism." Biochemistry (Moscow) Supplement Series B: Biomedical Chemistry 5, no. 2 (May 24, 2011): 152-157. doi:10.1134/s1990750811020053.

[9] Kozłowska A., D. Szostak-Węgierek. "Flavonoids - Food Sources, Health Benefits, and Mechanisms Involved”. In: Mérillon J.M., K.G. Ramawat “Bioactive Molecules in Food”. Springer. Cham, 2017. 1-27. doi: 10.1007/978-3-319-54528-8. 
[10] Shashkina M.Y., P.N. Shahkin, A.V.Sergeev. "Carotenoids in human health and prevention of diseases". Russian Biotherapeutical Journal, vol. 9, no 1 (2010): 71-86.

[11] Shashkina M.Y., P.N. Shahkin, A.V.Sergeev. "Carotenoids as a base or cancer chemoprevention". Russian Biotherapeutical Journal, vol.8, no 4 (2009): 91-98.

[12] Torregrosa-Crespo, Javier, Zaida Montero, Juan Fuentes, Manuel Reig García-Galbis, Inés Garbayo, Carlos Vílchez, and Rosa Martínez-Espinosa. "Exploring the Valuable Carotenoids for the Large-Scale Production by Marine Microorganisms." Marine Drugs 16, no. 6 (June 8, 2018): 203. doi:10.3390/md16060203.

[13] Cadenas, E., and L. Packer. Handbook of Antioxidants, 2nd Ed. Marcel Dekker. New York, 2002.

[14] Pawar H.R., S. S. Bhosale, N. D. Derle. "Use of liposomes in cancer therapy: a review”. International Journal of Pharmacological Science and Research, vol. 3, no 10 (2012): 3585-3590. doi:10.13040/IJPSR.0975-8232.3(10).3585-90.

[15] Shubenkova E., O. Chzhu, Y. Lobova, I. Lutayeva. "Study the influence of extraction conditions on elicitation of biologically active substances with antioxidant properties". Novosibirsk State Pedagogical University Bulletin 3, no 5 (2013): 144-148.

[16] Maksimova T.V., I.N. Nikulina, V.P. Pakhomov, E.I. Shkarina, Z.V. Chumakova, A.P. Arzamastsev. "Method for determining antioxidation activity”. Patent RU2170930C1 (2001).

[17] Hungerford, David A. "Leukocytes Cultured from Small Inocula of Whole Blood and the Preparation of Metaphase Chromosomes by Treatment with Hypotonic KCL.” Stain Technology 40, no. 6 (January 1965): 333-338. doi:10.3109/10520296509116440.

[18] Prarthana, J., and K.R. Maruthi. "Fresh Water Algae as a Potential Source of Bioactive Compounds for Aquaculture and Significance of Solvent System in Extraction of Antimicrobials." Asian Journal of Scientific Research 12, no. 1 (January 1 , 2019): 18-28. doi:10.3923/ajsr.2019.18.28.

[19] Messyasz, Beata, Izabela Michalak, Bogusława Łęska, Grzegorz Schroeder, Bogusława Górka, Karolina Korzeniowska, Jacek Lipok, et al. "Valuable Natural Products from Marine and Freshwater Macroalgae Obtained from Supercritical Fluid Extracts." Journal of Applied Phycology 30, no. 1 (September 7, 2017): 591-603. doi:10.1007/s10811-017-1257-5.

[20] Azarova O.P. (Chzhu), E.G. Shubenkova, A.K Chernyshev. "Liposomal nanocapsule”. Patent RU2462236C2 (2012). 